Superalloys 2012: 12 $^{\text {th }}$ International Symposium on Superalloys

\title{
The Effect of Crystal Orientation and Temperature on Fatigue Crack Growth of Ni-based Single Crystal Superalloy
}

\author{
Hiroyuki KAGAWA ${ }^{1}$, Yasuhiro MUKAI ${ }^{1}$ \\ ${ }^{1}$ The Kansai Electric Power Co., Inc.; 3-11-20, Nakoji, Amagasaki, Hyogo, 661-0974, Japan
}

Keywords: Ni-based superalloy, Single crystal, Fatigue crack propagation rate

\begin{abstract}
Crack propagation tests were performed by using compact specimens made of Ni-based single crystal superalloy CMSX-4. Three types of specimens with different orientation were machined. The combinations of loading directions and machined

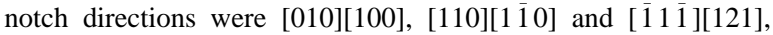
respectively. Tests were performed at room temperature, $500^{\circ} \mathrm{C}$, $700^{\circ} \mathrm{C}$ and $900^{\circ} \mathrm{C}$ for each orientation specimen.

In all specimens tested at room temperature, cracks propagated along slip planes (stage-I), resulting fracture surfaces composed of slip planes. In specimens tested at elevated temperature, cracks propagated along the machined notch direction (stage-II) at the beginning of the tests. FEM calculations were conducted for evaluating the relations between mode I-III SIFs and crack length for specimen with inclined cracks.

Methods for evaluating stage-I and stage-II crack propagation rates were proposed. Stage-I crack propagation rates were correlated within the range of factor of 4 using resolved shear stress intensity factor range which was calculated from shear stress on a slip plane parallel to the stage-I crack plane. Stage-II crack propagation rates of all specimens were correlated in the range of factor of 3 with energy release rate calculated using anisotropic elastic moduli. It was suggested that the difference in the elastic moduli caused by the difference between specimen orientation and tested temperature influenced primarily stage-II crack propagation rate.
\end{abstract}

While stage-II cracking was predominant, stage-I fracture surfaces were initiated near side faces in some specimens, and the areas of the stage-I fracture surface tended to expand to the inner regions of the specimens with crack propagation. The transition from stage-II to stage-I was evaluated by using resolved shear stress intensity factor range under plane stress condition.

\section{Introduction}

Blades and nozzles of gas turbine power plants are exposed to high temperature combustion gas during operation. In order to decrease temperature of a substrate, they are air-cooled internally. Thermal barrier and corrosion-resistant coatings are often sprayed on the outer surface. Though these treatments decrease substrate temperature and reduce damage efficiently, low ductility of coatings at relatively low temperature and thermal stress due to internal air-cooling sometimes causes coating cracks [1].

At new $1500^{\circ} \mathrm{C}$ class gas turbine power plants, directionally solidified Ni-based superalloys are used for blade applications. In this type of superalloy, crack propagation behavior may be affected by crystal orientation. Since components of gas turbines are expensive, methods for evaluating the effect of crystal orientation on crack propagation behavior are required to make an adequate run-repair-replace criterion and to lower maintenance costs of these components.

In this study, Ni-based single crystal superalloy was used to examine the effect of crystal orientation on crack propagation behavior. Many reports were already published describing anisotropic behavior of single crystal superalloys: tensile strength [2,3], fatigue strength [4-6], crack propagation behavior [7-24]. In regard to crack propagation behavior of single crystal superalloys, it is well known that cracks tend to propagate on $\{111\}$ slip planes at low temperature, while cracks usually propagate normal to loading direction independent of crystal orientation at high temperature [7-9]. The former cracking behavior is called stage-I cracking, and the latter is called stage-II cracking. Several studies were performed investigating factors that influence crack propagation rate (CPR) and behavior, namely crystal orientation [7-11], temperature [12-14], environment [10, 15-17], loading frequency [14,18], microstructure and strength of $\gamma^{\prime}$ phase [19]. CPR of polycrystals is usually evaluated by mode I stress intensity factor (SIF) range $\Delta K_{\mathrm{I}}$. In case of single crystals, several parameters were proposed to evaluate CPR in addition to $\Delta K_{\mathrm{I}}$, namely effective SIF range $\Delta K_{\text {eff }}$ [7-9], resolved shear SIF range $\Delta K_{\mathrm{RSS}}[18,21]$ and $\Delta K_{\tau}[22]$, resolved normal SIF range $\Delta K_{\mathrm{NS}}$, $\Delta K_{\mathrm{r}(\mathrm{eq})}[18,21]$ calculated from $\Delta K_{\mathrm{RSS}}$ and $\Delta K_{\mathrm{NS}}$.

The criterion of the transition between stage-I and stage-II cracking were also studied [6, 17, 18, 20, 23]. Stage-I cracking prefers low temperature, high frequency, high SIF and vacuum condition, while stage-II cracking prefers high temperature, low frequency, low SIF and oxidizing atmosphere. Though a great number of prior studies have been carried out, the crack propagation behavior of single crystal superalloys are still not understood completely. No method has been developed for evaluating CPR under the load-temperature cycle that components experience in power plant applications.

In this study, crack propagation tests were performed with three specimen orientations at $\mathrm{RT}, 500^{\circ} \mathrm{C}, 700^{\circ} \mathrm{C}$ and $900^{\circ} \mathrm{C}$. Tensile tests were additionally performed to estimate anisotropic elastic modulus and tensile strength at temperature ranging from RT to $1000^{\circ} \mathrm{C}$. Three-dimensional FEM calculations were also performed for calculating mode I-III SIFs. The FE results were utilized to prepare the methods for evaluating stage-I and stage-II CPR. Finally, the transition criterion from stage-II to stage-I was studied. 

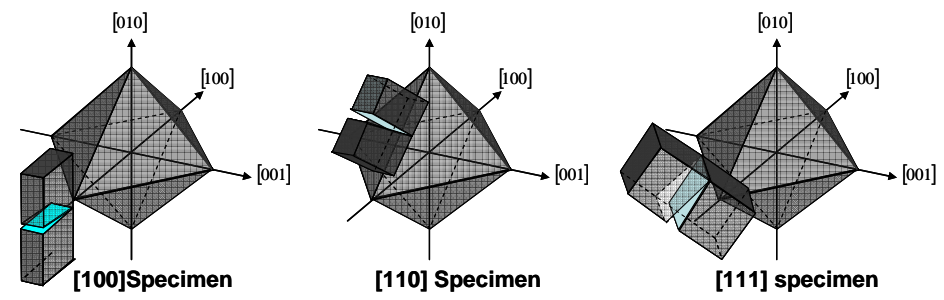

Figure 1 Arrangement of octahedral slip systems for three kinds of specimens with different orientations.

\section{Experimental and analytical procedures}

\section{Material}

Single crystal superalloy CMSX-4 was cast in the shape of $100 \mathrm{~mm} \times 150 \mathrm{~mm} \times 15 \mathrm{~mm}$ plates. The weight $\%$ chemistry of the materials was $6.4 \% \mathrm{Cr}, 9.5 \% \mathrm{Co}, 3.0 \% \mathrm{Re}, 6.3 \% \mathrm{~W}, 0.6 \% \mathrm{Mo}$, $6.5 \% \mathrm{Ta}, 1.0 \% \mathrm{Ti}, 5.4 \% \mathrm{Al}, 0.10 \% \mathrm{Hf}$, and balance $\mathrm{Ni}$. Two kinds of plates with different orientation were cast. The combinations of the longitudinal direction and width direction were [010][100] and [010][101], respectively. Four plates were made for each orientation. The misorientations of the former is $1.5^{\circ}-6.5^{\circ}$ to the longitudinal direction and $1.5^{\circ}-5^{\circ}$ to the width direction, and those of the latter is $1.5^{\circ}-5^{\circ}$ and $0^{\circ}-3^{\circ}$, respectively. The cast plates were solution treated at $1586 \mathrm{~K}$ for 2 hours, $1573 \mathrm{~K}$ for 10 hours, $1586 \mathrm{~K}$ for 2 hours, 1589K for 2 hours, $1591 \mathrm{~K}$ for 2 hours and $1594 \mathrm{~K}$ for 2 hours, and aged at $1353 \mathrm{~K}$ for 4 hours and $1144 \mathrm{~K}$ for 20 hours.

\section{$\underline{\text { Tensile tests }}$}

To obtain elastic moduli and tensile strength, tensile tests were performed at RT, $400^{\circ} \mathrm{C}, 500^{\circ} \mathrm{C}, 600^{\circ} \mathrm{C}, 700^{\circ} \mathrm{C}, 800^{\circ} \mathrm{C}, 900^{\circ} \mathrm{C}$ and $1000^{\circ} \mathrm{C}$ in air. Three types of specimens with different orientation were machined with $20 \mathrm{~mm}$ length and $4 \mathrm{~mm}$ diameter. The tensile direction in those specimens were [100], [110], and [111]. The applied strain rate was $7.5 \% / \mathrm{min}$.

\section{Crack propagation tests}

Crack propagation tests were performed by using compact specimens whose width was $W=40 \mathrm{~mm}$, thickness was $B=10 \mathrm{~mm}$ and machined notch length was $a_{0}=12 \mathrm{~mm}$. Three types of specimens with different orientation were machined from casted plates. The combinations of loading directions and machined

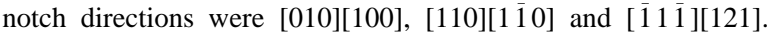
These are described as [100], [110] and [111] specimens in the following sections. Figure 1 shows the relations of specimens and octahedral slip plane. In each orientation specimen, tests were performed at $\mathrm{RT}, 500^{\circ} \mathrm{C}, 700^{\circ} \mathrm{C}$ and $900^{\circ} \mathrm{C}$. A total of 12 tests were performed. Stress ratio was 0.05 and loading frequency was $10 \mathrm{~Hz}$. All tests were performed according to ASTM E647 [24], and crack length was measured by unloading compliance method. In each specimen, pre-crack was introduced under each tested temperature and loading condition. Tests were performed under constant load except for [110] specimen tested at $900^{\circ} \mathrm{C}$. It was tested under constant load before crack length reached $6 \mathrm{~mm}$, and then tested with decreasing load.
Finite element analyses

As stated above, the crack length was measured by unloading compliance method, where crack was assumed to propagate along machined notch direction. However, cracks in all specimens tested at RT and some specimens tested at elevated temperature grew at an inclined angle. Therefore, FEM calculations were performed for evaluating the relationship between unloading compliance and crack length for specimens with inclined cracks. FEM calculations were also conducted for evaluating the relations between mode IIII SIFs and crack length for specimen with inclined cracks. In FEM calculations, anisotropic elastic moduli $E, G$ and $v$ which were obtained from the tensile tests were used.

\section{Results of experiments and analyses}

\section{Tensile tests}

Figure 2 shows tensile strength and $0.2 \%$ yield strength obtained from the tensile tests. Tensile strengths of [111] specimens below $600^{\circ} \mathrm{C}$ were the highest compared with [100] and [110] specimens. It is because Schmid factor of octahedral slip system in [111] specimen is the lowest. The ratio of Schmid factor in [100] and [110] specimens to that in [111] specimen are 1.5, and the ratio of the tensile strength in [111] specimen to that in [110] specimen was 1.67 at RT, 1.55 at $400^{\circ} \mathrm{C}$ and 1.49 at $500^{\circ} \mathrm{C}$, which were close to the ratio of Schmid factors of these specimens. The tensile strengths of [111] specimens decreased with increase in test temperature probably due to the activation of cubic slip system. The strengths of [100] specimen showed peak values at $800^{\circ} \mathrm{C}$ due to the dislocation pinning of octahedral slip system caused by dislocation's partial cross-slipping to cubic slip system. The tendencies stated above agreed with previous studies qualitatively [2, 3].

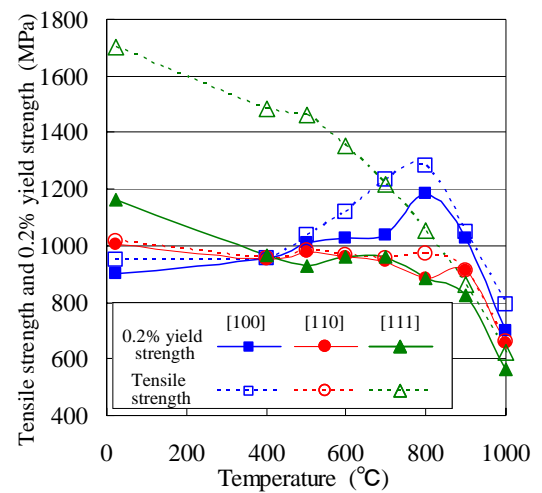

Figure 2 Tensile strength and $0.2 \%$ yield strength. 
Table I shows Young's moduli directly obtained by the tensile tests. The three independent elastic constants $(E, G$ and $v)$ were estimated by following way. In each orientation specimen, Young's moduli were linearly-approximated as a function of temperature. Elastic modulus $E$ at each temperature was presumptively equal to linearly-approximated Young' modulus of [100] specimen. Referring to previous report [25], Poisson ratio $v$ was assumed to be $v=0.4$ in the range from RT to $900^{\circ} \mathrm{C}$. At each temperature, moduli of rigidity $G$ were calculated by using linearly-approximated Young' moduli of [110] and [111] specimens with $E$ and $v$ obtained above. Finally, moduli of rigidity $G$ were estimated as the average value of the two calculated values. Note that, since Young's moduli of [110] and [111] at $1000^{\circ} \mathrm{C}$ were not measured, $G$ at $1000^{\circ} \mathrm{C}$ was determined by means of simple extrapolation from the values at lower temperature. Table II shows the estimated independent elastic constants.

Table I Young's moduli obtained from tensile tests.

\begin{tabular}{|c|c|c|c|}
\hline$\left({ }^{\circ} \mathrm{C}\right)$ & {$[100]$} & {$[110]$} & {$[111]$} \\
\hline 23 & 156 & 280 & - \\
\hline 400 & 158 & 247 & 290 \\
\hline 500 & 126 & 194 & 277 \\
\hline 600 & 117 & - & 293 \\
\hline 700 & 119 & 196 & 253 \\
\hline 800 & 105 & 189 & 268 \\
\hline 900 & 102 & - & 220 \\
\hline 1000 & 104 & - & - \\
\hline
\end{tabular}

Table II Estimated three independent elastic constants in material coordinate system.

\begin{tabular}{|c|c|c|c|}
\hline$\left({ }^{\circ} \mathrm{C}\right)$ & $E(\mathrm{GPa})$ & $v$ & $G(\mathrm{GPa})$ \\
\hline 23 & 162 & 0.4 & 138 \\
\hline 400 & 137 & 0.4 & 116 \\
\hline 500 & 131 & 0.4 & 111 \\
\hline 600 & 124 & 0.4 & 105 \\
\hline 700 & 118 & 0.4 & 99 \\
\hline 800 & 111 & 0.4 & 94 \\
\hline 900 & 105 & 0.4 & 88 \\
\hline 1000 & 98 & 0.4 & 82 \\
\hline
\end{tabular}

Crack propagation behavior

Figure 3 shows fracture surfaces. All specimens tested at room temperature showed stage-I fracture, while all specimens tested at elevated temperature showed stage-II fracture at the beginning of tests. The angle between machined notch and crack propagating direction at specimen side-face is defined as $\theta$. At room temperature, fracture surfaces were inclined at $\theta=45^{\circ}$ for [100]RT, $\theta=90^{\circ}$ for [110]RT, and $\theta=55^{\circ}$ for [111]RT specimen, respectively. [100]RT and [110]RT specimens formed large ridges in their fracture surfaces. These ridges were composed of (i11) and ( $\overline{1} 1 \overline{1})$ slip planes. [111]RT specimen formed fine ridges in its fracture surfaces as shown in Figure 4. These ridges were composed of (111) and (111) slip planes.

Figure 5 shows side faces of specimens tested above $500^{\circ} \mathrm{C}$, in which the crack propagated from right to left. A white arrow in each figure corresponds to a machined notch tip. Above $500^{\circ} \mathrm{C}$, most of cracks propagated approximately along the notch direction at the beginning of tests. While stage-II cracking was predominant, stage-I fracture surfaces were initiated near side faces in some specimens, and the areas of the stage-I propagation expanded to the inner side of the specimens with crack propagation. Notably, at $[111] 500^{\circ} \mathrm{C}$ and $[111] 900^{\circ} \mathrm{C}$, stage-I fracture surfaces were expanded to the whole thickness, and they were inclined at $\theta=55^{\circ}$ and $\theta=30^{\circ}$ to the notch direction, respectively. Circles in Figure 5 indicate the transition points from stage-II to stage-I at specimen side faces.

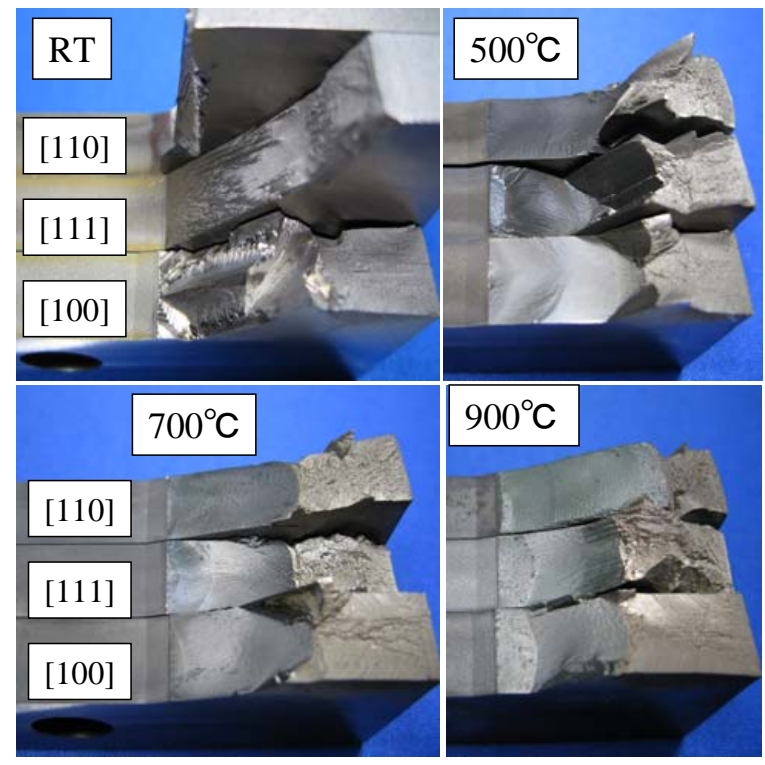

Figure 3 Fracture surfaces

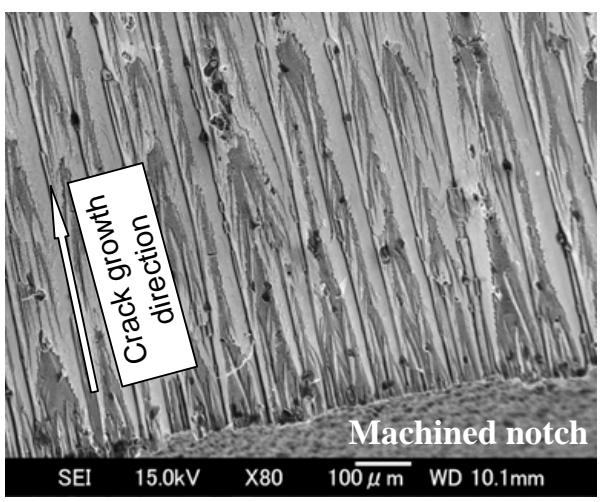

Figure 4 Fracture surfaces of [111] specimen tested at room temperature.

Figure 6 shows the fracture surface of the $[110] 500^{\circ} \mathrm{C}$ specimen which had a valley at specimen mid-thickness. This valley was caused by stage-I cracking on $\{111\}$ slip plane similar to that of [110]RT specimen. Figure 7 a shows the fracture surface of [111] $900^{\circ} \mathrm{C}$. In $[111] 900^{\circ} \mathrm{C}$, the fracture surface showed V-shape patterns with an angle of $60^{\circ}$ in the early stage of the test (Figure $7 b$ ), and changed to cuboidal patterns (Figure 7c), and finally changed to stage-I ridge pattern which was formed by coalescing of cuboidal patterns. V-shape patterns and cuboidal patterns indicated that cracking occurred by the activation of octahedral slip and cubic slip, respectively. 


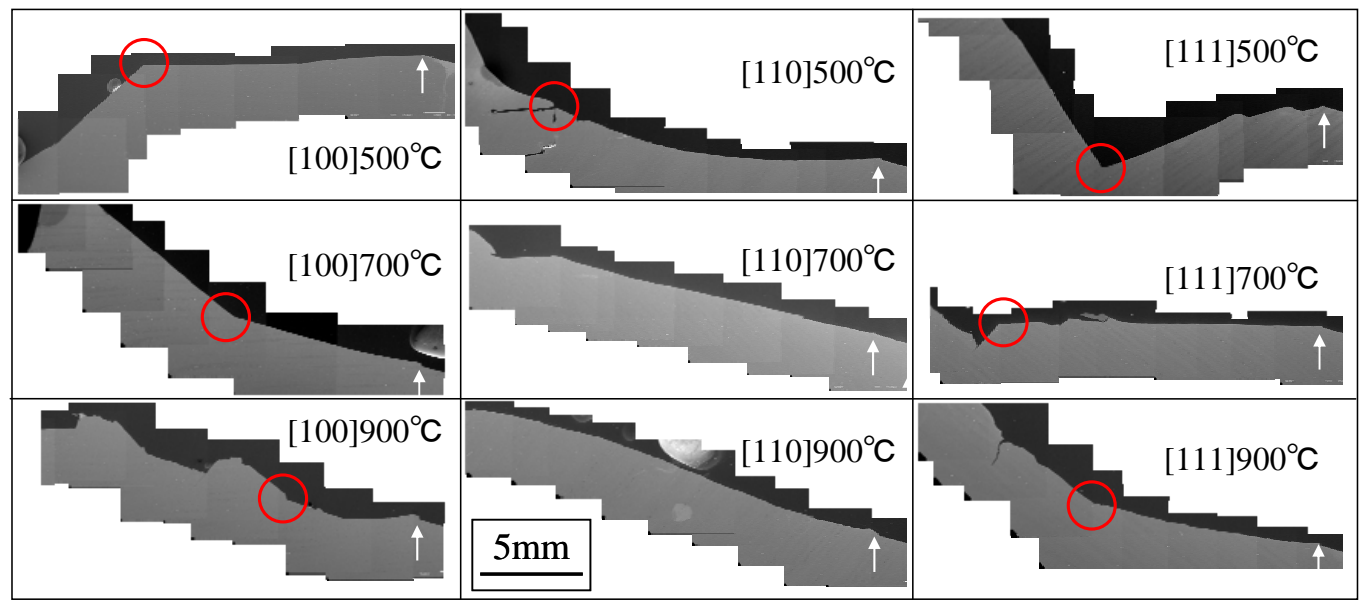

Figure 5 Side face of fractured specimens. Circles indicate the transition points from stage-II to stage-I cracking at side faces of specimens. Arrows show machined notch tips.

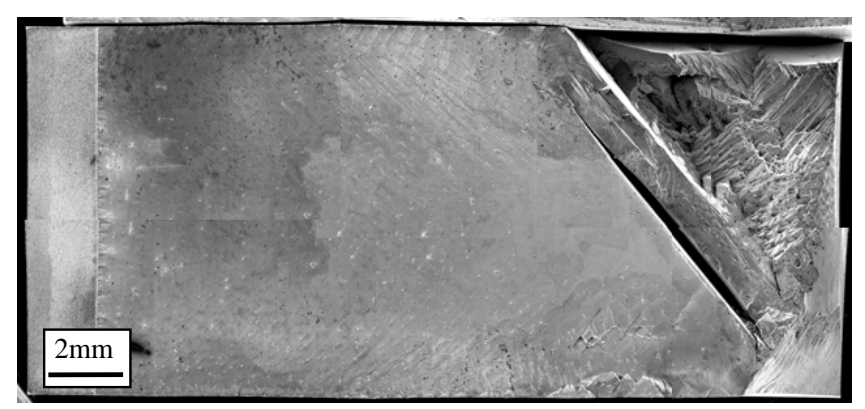

Figure 6 Fracture surface of [110] specimen tested at $500^{\circ} \mathrm{C}$.

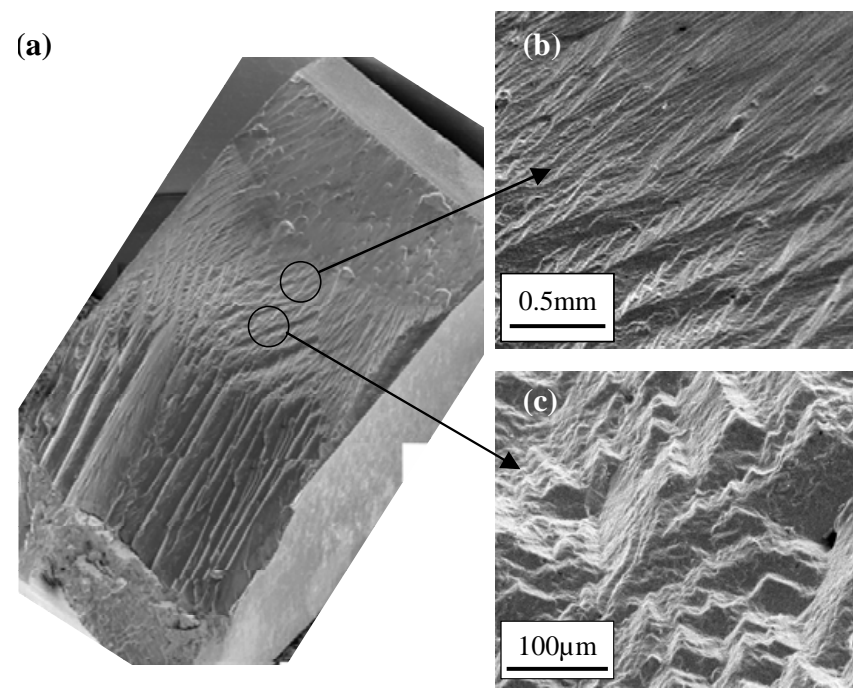

Figure 7 (a): Fracture surface of [111] specimen tested at $900^{\circ} \mathrm{C}$.

(b): Observation of octahedral slip.

(c): Observation of cubic slip.

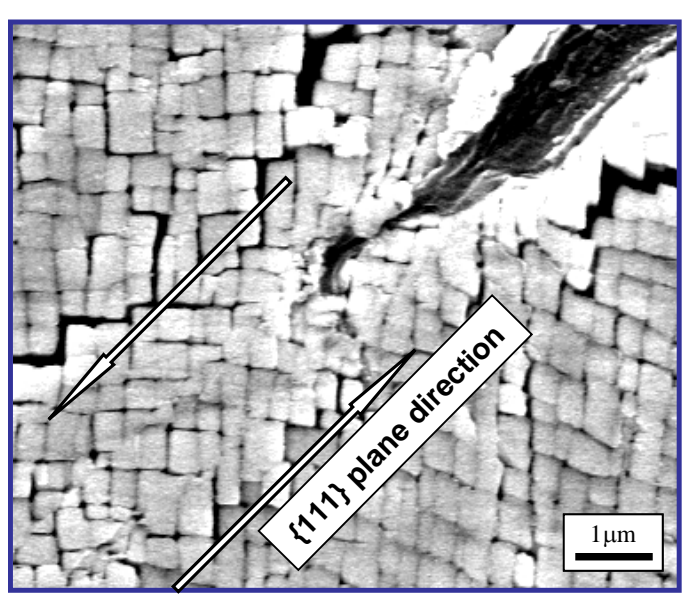

(a) Stage-I secondary crack in [100] specimen tested at $500^{\circ} \mathrm{C}$

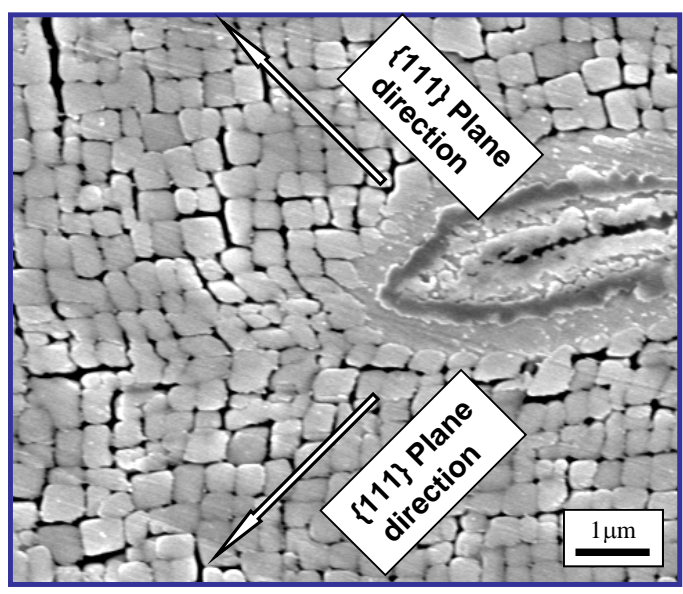

(b) Stage-II secondary crack in [100] specimen tested at $900^{\circ} \mathrm{C}$

Figure 8 Side viewings of secondary cracks. 
Figure 8a shows the side view of the secondary crack of $[100] 500^{\circ} \mathrm{C}$ specimen where stage-I cracking has occurred. The crack tip was sharp, and some slip lines emanating from the crack tip along secondary crack direction were observed. On the other hand, Figure $8 \mathrm{~b}$ shows the side view of the secondary crack of $[100] 900^{\circ} \mathrm{C}$ specimen where stage-II cracking was predominant. The crack tip was blunt, and $\gamma^{\prime}$ phase was deformed preferentially in front of the crack tip at angles of $\pm 45^{\circ}$ from the secondary crack plane.

\section{$\underline{\text { FE analysis }}$}

The influence of crack inclination to the loading direction on the unloading compliance was evaluated by FEM calculation. FEM calculation was performed using MSC-Marc 2010 [28]. For this purpose, two-dimensional FEM calculations were carried out under plane strain condition. The influence of three-dimensional crack inclination on SIFs was also evaluated by FE analyses. Figure 9 shows FE model of [100]RT as an example. SIFs were calculated using stress distribution at crack tip. Since fracture surfaces of [100]RT specimen had thickness-directional symmetry, halves of the whole specimen thickness were modeled. Calculated SIFs were corrected by following equation.

$$
K_{i}=\frac{F}{B W} \cdot f_{i}\left(\frac{a^{\prime}}{W}\right) \cdot \sqrt{\pi a^{\prime}} \quad(\mathrm{i}=\mathrm{I}, \mathrm{II}, \mathrm{III})
$$

$F$ is the loading force, $B$ is the thickness, $W$ is the width. $a$ ' is the projected crack length. With the exception of [110]RT specimen, $a^{\prime}$ is calculated by $a^{\prime}=a_{0}+\Delta a \cdot \cos \theta$ where $\Delta a$ is crack length from machined notch tip. In case of [110]RT specimen where crack propagated as an angle of $\theta=90^{\circ}, a^{\prime}$ is calculated by $a^{\prime}=a_{0}+\Delta a$. The shape function $f_{\mathrm{i}}\left(a^{\prime} / W\right)$ is determined by using FE results in each specimen which showed stage-I cracking. Figure 10 shows the shape function $f_{\mathrm{i}}\left(a^{\prime} / W\right)$. For evaluating stage-II CPR, anisotropic energy release rate $g$ was additionally calculated by virtual crack extension method.

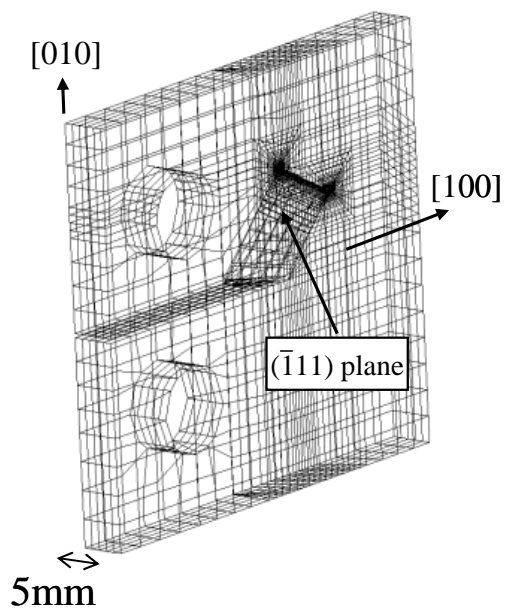

Figure 9 FEM model for [100] specimen tested at room temperarture.
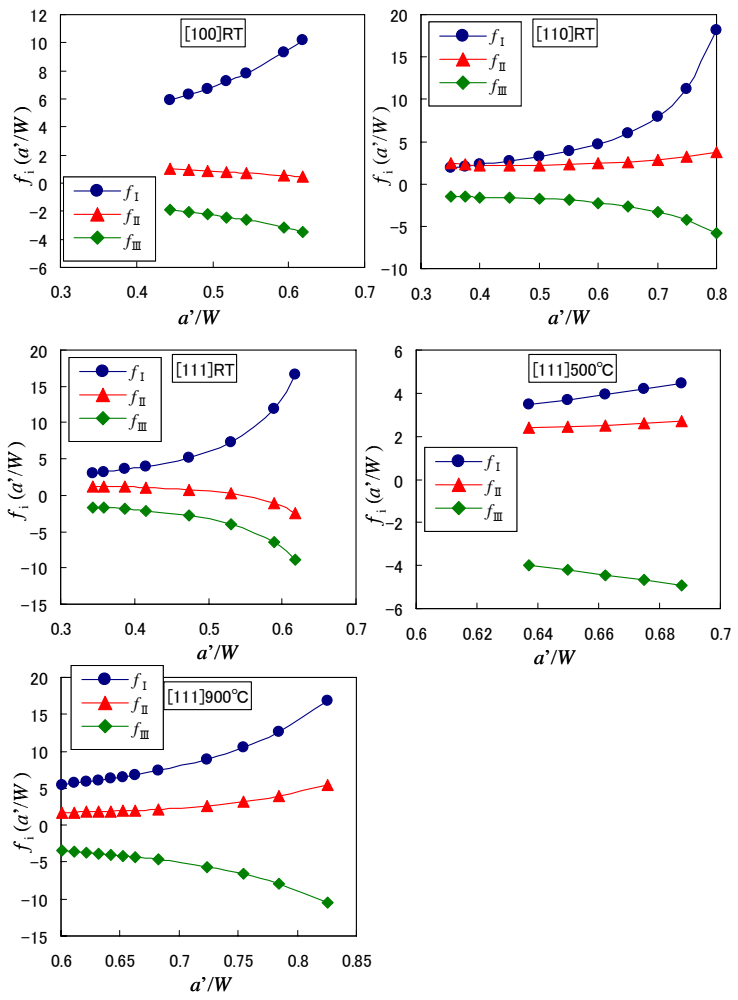

Figure 10 Shape functions for mode I-III stress intensity factors of five specimens where stage-I cracking were observed.

\section{Discussion}

\section{$\underline{\text { Stage-I crack propagation rate }}$}

Figure 8 indicated that the crack propagation mechanisms of stage-I and stage-II were different. In case of stage-I cracking, crack propagated along the slip lines which caused cumulative fatigue damage on a slip plane. The amplitude of slip deformation of each slip system is related to the resolved shear SIF range $\Delta K_{\mathrm{RSS}}$, which is calculated by shear stress resolved on $\{111\}$ slip plane in <101> slip direction. Decohesion of damaged slip plane is caused by normal stress on the slip plane whose intensity can be defined by resolved normal SIF range $\Delta K_{\mathrm{NS}}$. Since a slip plane has three slip directions, there are three $\Delta K_{\mathrm{RSS}}$ on a slip plane. Though in some previous studies largest $\Delta K_{\mathrm{RSS}}$ among twelve slip systems was used to correct stage-I CPR, there are three $\Delta K_{\mathrm{RSS}}$ on a slip plane. When crack propagates on a slip plane, few slip systems on the cracking plane are thought to act. Therefore, resolved shear SIF range $\Delta K_{\tau}$ was used, which is calculated by shear stress resolved on a slip plane and to an arbitrary direction in which shear stress is maximized. By using the SIF parameters stated above, stage-I CPR was evaluated. Stress distribution around crack tip is calculated by the following equation.

$\sigma_{i j}=\frac{1}{\sqrt{2 \pi r}}\left(K_{\mathrm{I}} \cdot f_{i j}^{\mathrm{I}}(\theta)+K_{\mathrm{II}} \cdot f_{i j}^{\mathrm{II}}(\theta)+K_{\mathrm{III}} \cdot f_{i j}^{\mathrm{III}}(\theta)\right)$ 


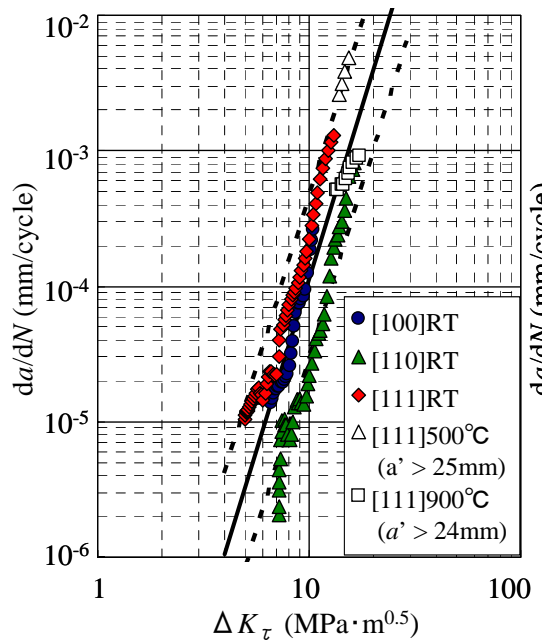

(a) $\mathrm{d} a / \mathrm{d} N$ vs $\Delta K_{\tau}$

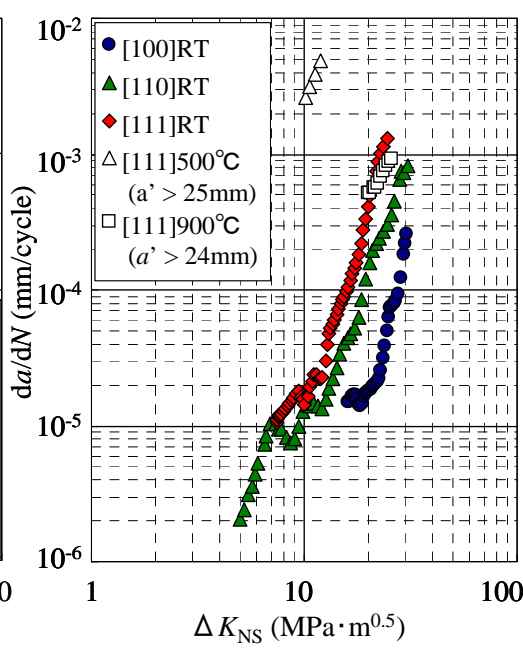

(b) da/d $N$ vs $\Delta K_{\mathrm{NS}}$

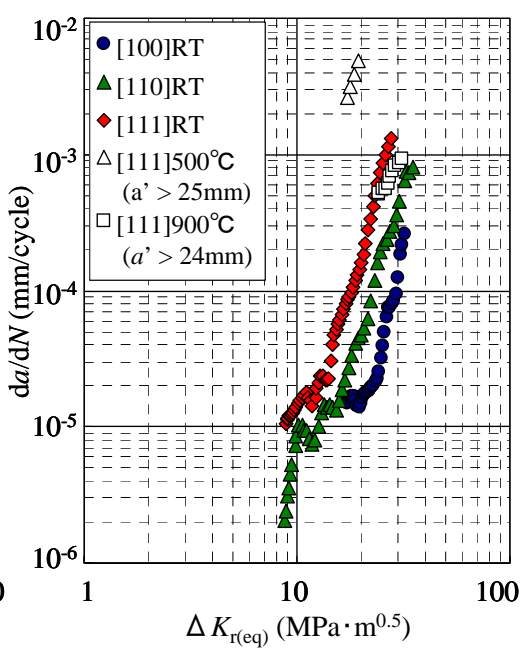

(c) $\mathrm{d} a / \mathrm{d} N$ vs $\Delta K_{\text {r(eq) }}$

Figure 11 Stage-I fatigue crack propagation rates

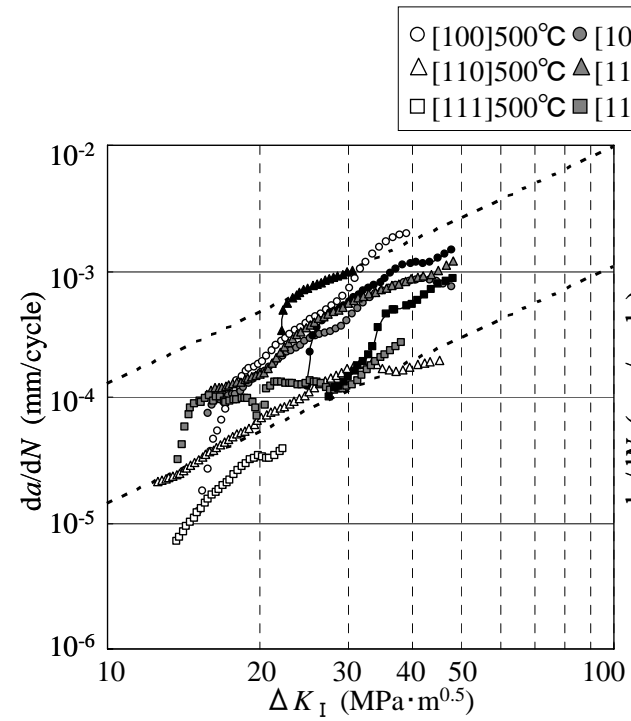

(a) $\mathrm{d} a / \mathrm{d} N$ vs $\Delta K_{\mathrm{I}}$

Figure 12 Stage-II fatigue crack propagation rates

$\theta$ is the angle of the crack propagating direction, and $r$ is distance from crack tip. $f_{\mathrm{ij}}{ }^{\mathrm{I}}(\theta)-f_{\mathrm{ij}}{ }^{\mathrm{III}}(\theta)$ for anisotropic material are described in the reference $[29,30]$.

Considering the $x^{\prime}-y^{\prime}-z^{\prime}$ coordinate in which y'-axis is parallel to arbitrary slip plane normal, $K_{\tau}, K_{\mathrm{NS}}$ and $K_{\mathrm{r}(\mathrm{eq})}$ are calculated as follows.

$$
\begin{aligned}
& K_{\tau}=\lim _{r \rightarrow 0} \sqrt{2 \pi r} \sqrt{\sigma_{x^{\prime} y^{\prime}}{ }^{2}+\sigma_{y^{\prime} z^{\prime}}{ }^{2}} \\
& K_{N S}=\lim _{r \rightarrow 0} \sqrt{2 \pi r} \cdot \sigma_{y^{\prime} y^{\prime}} \\
& K_{r(e q)}=\sqrt{K_{\tau}^{2}+K_{N S}{ }^{2}}
\end{aligned}
$$

In case of stage-I cracking, $\theta$ is 0 since crack propagate on a slip plane. $K_{\tau}$ and $K_{\mathrm{NS}}$ are calculated as follows.

$$
\begin{aligned}
& K_{\tau}=\lim _{r \rightarrow 0} \sqrt{2 \pi r} \sqrt{\sigma_{x^{\prime} y^{\prime}}{ }^{2}+\sigma_{y^{\prime} z^{\prime}}{ }^{2}}=\sqrt{K_{\mathrm{II}}{ }^{2}+K_{\mathrm{III}}{ }^{2}} \\
& K_{N S}=\lim _{r \rightarrow 0} \sqrt{2 \pi r} \cdot \sigma_{y^{\prime} y^{\prime}}=K_{\mathrm{I}}
\end{aligned}
$$

Figure 11a-c show stage-I CPR plotted against $\Delta K_{\tau}, \Delta K_{\mathrm{NS}}$ and $\Delta K_{\mathrm{r}(\mathrm{eq})}$, respectively. It can be seen from Figure 11 that stage-I CPR of the five specimens shows the best correlation with stage-I $\mathrm{CPR}(\mathrm{mm} / \mathrm{cycle})$ and $\Delta K_{\tau}\left(\mathrm{MPa} \cdot \mathrm{m}^{0.5}\right)$. That was approximated by the following equation.

$$
d a / d N=8.69 \cdot 10^{-10} \Delta K_{\tau}^{5.11}
$$


The solid-line in Figure 11a corresponds to equation (8) and dotted-lines correspond to the factor of 4 of equation (8). When stage-I CPR was corrected by $\Delta K_{\mathrm{NS}}$, CPR data of [111]RT specimen was plotted on lower $\Delta K_{\mathrm{NS}}$ side compared to those of [100]RT and [110]RT. It is because that the crack inclination angle to the thickness direction of [111]RT was larger than those of [100]RT and [110]RT. The same tendency was observed when $\Delta K_{\mathrm{r}(\mathrm{eq})}$ was employed. From the above, the influence of normal stress on stage-I cracking was small compared to shear stress.

In this study, however, crack closure was not measured. Another fatigue crack propagation tests were performed at $\mathrm{RT}, 500^{\circ} \mathrm{C}$, and $900^{\circ} \mathrm{C}$ using same specimen geometry, material, and stress ratio. As the result, closure ratio $U$ at room temperature was $0.88-1.00$, so crack closure at room temperature was thought to be small. Crack closures at $500^{\circ} \mathrm{C}$ and $900^{\circ} \mathrm{C}$ were also measured to be small.

\section{$\underline{\text { Stage-II crack propagation rate }}$}

From Figure $8 \mathrm{~b}$, it is assumed that stage-II crack propagated by alternating slip at the crack tip. As it is difficult to determine activation slip systems which contributed to the deformation at crack tip for stage-II cracking, $\Delta K_{\tau}, \Delta K_{\mathrm{NS}}$ and $\Delta K_{\mathrm{r}(\mathrm{eq})}$ were not used to evaluate stage-II CPR. Figure 12a and $12 \mathrm{~b}$ shows the stage-II CPR plotted against $\Delta K_{\mathrm{I}}$ and energy release rate $g$ $(\mathrm{MPa} \cdot \mathrm{m})$, respectively. Stage-II CPR showed better correlation with energy release rate $g$ in which the changes of elastic moduli caused by the difference of specimen orientation and tested temperature were considered. Dotted-lines in Figure 12 show the range of factor of 4 in each graph. It is suggested that anisotropic elastic moduli influenced CPR primarily. The relation between stage-II CPR (mm/cycle) and $g$ (MPa-m) was corrected by the following equation.

$$
d a / d N=C \cdot g^{m}
$$

Using common coefficient $m=1.29$, coefficient $C$ for each specimen was calculated. Figure 13 shows the relation between the coefficient $C$ and temperature.

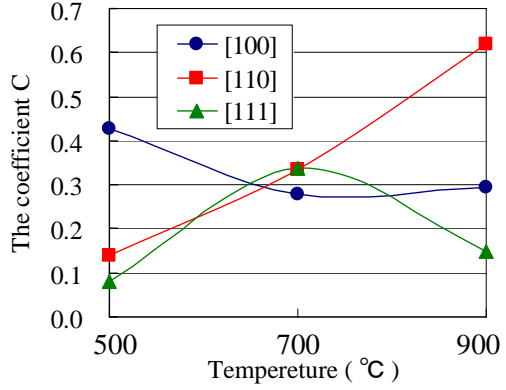

Figure 13 Coefficient $C$ of equation (8) as a function of temperature.

Generally, CPR is increased with increasing temperature. However, the coefficient $C$ of [100] specimen is larger at $500^{\circ} \mathrm{C}$ compared to other temperatures, and that at $700^{\circ} \mathrm{C}$ is slightly less than that at $900^{\circ} \mathrm{C}$. D.W.Maclachan et.al [6] performed the fatigue tests of single crystal superalloys CMSX-4 and RR2000 at $550^{\circ} \mathrm{C}$, $750^{\circ} \mathrm{C}$ and $950^{\circ} \mathrm{C}$ under $10 \mathrm{~Hz}$, and found that fatigue life at $550^{\circ} \mathrm{C}$ was shorter than those at the other temperatures. They pointed out that the dependence of high-cycle fatigue strength on temperature was related to the dependence of $\gamma^{\prime}$ strength on temperature. In this study, tensile strengths of [100] tensile specimen at $700^{\circ} \mathrm{C}$ and $900^{\circ} \mathrm{C}$ were higher than $500^{\circ} \mathrm{C}$ due to the increasing of critical resolved shear stress of octahedral slip system of $\gamma^{\prime}$ phase with increasing temperature. That was the reason why CPR of $[100] 700^{\circ} \mathrm{C}$ and $[100] 900^{\circ} \mathrm{C}$ were lower than that of $[100] 500^{\circ} \mathrm{C}$. On the other hand, the coefficient $C$ of [110] specimens increases with increasing temperature, and that of $[110] 900^{\circ} \mathrm{C}$ was the largest among all orientation and temperature specimens. The reason is as follows. The cubic slip system becomes easier to act by thermal activation above $600^{\circ} \mathrm{C}$ for [110] specimens in which cubic slip planes lie in $\pm 45^{\circ}$ direction from machined notch plane. The coefficient $C$ of [111] specimens is lower than the other orientation specimens. The reason is that in [111] specimens octahedral slip planes lied asymmetrical to the machined notch plane and therefore the alternating slip is difficult for stage-II cracking.

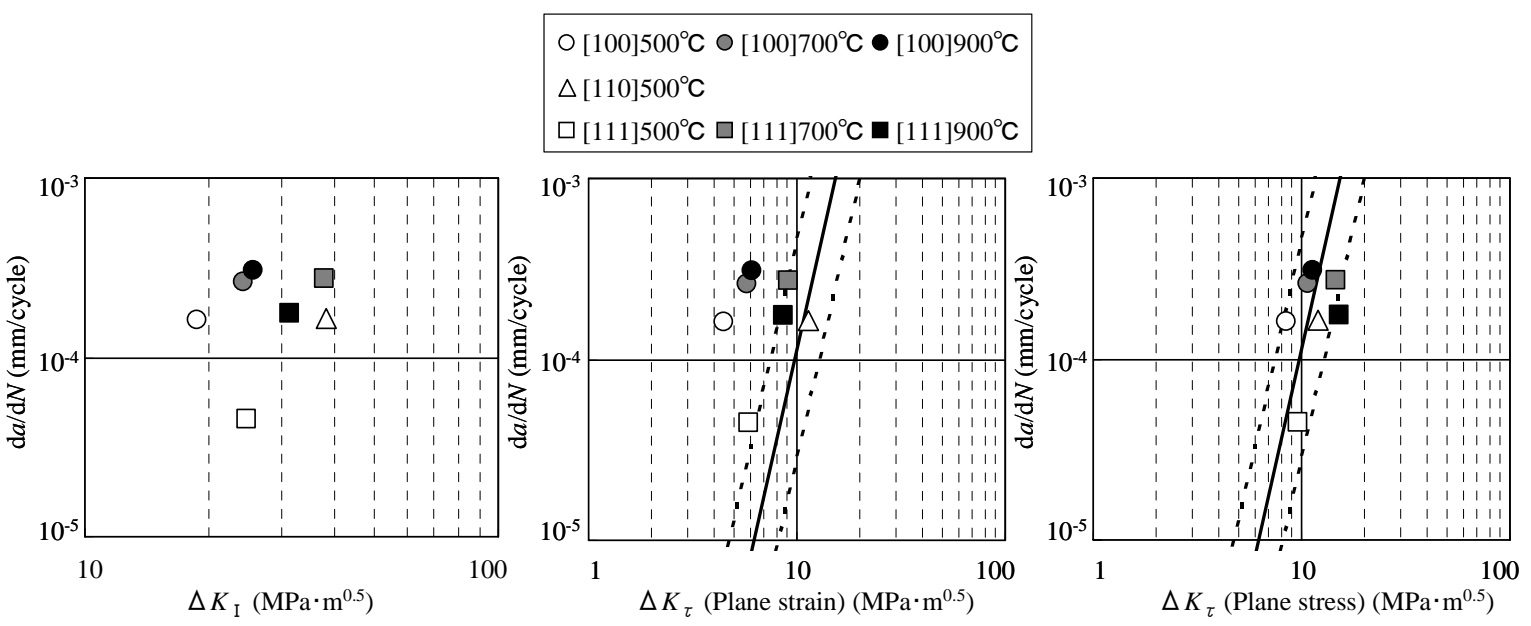

Figure 14 The relation between crack propagation rates and stress intensity parameters, where transitions from stage-II to stage-I were observed at specimens side faces. 
The transition from stage-II to stage-I cracking

As shown in Figure 5, the transition points from stage-II to stage-I differed with specimen orientation and temperature. Figure 14a shows the relation between CPR and $\Delta K_{\mathrm{I}}$ at each transition point described by circle in Figure 5. No relation can be seen between CPR and $\Delta K_{\mathrm{I}}$ of the transition points. Figure $14 \mathrm{~b}$ and $14 \mathrm{c}$ show the relation between CPR and $\Delta K_{\tau}$ under plane strain and plane stress conditions, respectively. $\Delta K_{\mathrm{\tau}}$ in Figure $14 \mathrm{~b}$ and $14 \mathrm{c}$ are the values on slip planes on which stage-I crack propagates, namely ( $\overline{1} 11)$ and $(\overline{1} 1 \overline{1})$ for [100] specimens, ( $\overline{1} 1 \overline{1})$ and $(\overline{1} 11)$ for $[110] 500^{\circ} \mathrm{C}$ specimen, $(\overline{1} 11)$ and $(11 \overline{1})$ for $[111] 500^{\circ} \mathrm{C}$ and $[111] 700^{\circ} \mathrm{C}$ specimens, and $(100)$ and $(001)$ for $[111] 900^{\circ} \mathrm{C}$ specimen. The solid-line and dotted-lines in Figure 14 represent equation (6) and the range of factor of 4 , respectively. From Figure 14c, transition points were plotted between dotted-lines by using $\Delta K_{\tau}$ under plane stress condition. Therefore, it can be assumed that the transition occurs when the relationship between CPR and $\Delta K_{\tau}$ under plane stress condition reach those of stage-I cracking. As shown in Figure 5 and Figure 6, the transition of [110] $500^{\circ} \mathrm{C}$ specimen was initiated from specimen side-face and inner surface at almost the same time. It was caused because, in the case of [110] specimens, $K_{\tau}$ under plane strain condition was equivalent to that under plane stress conditions.

Figure 15 shows the stage-II CPR plotted against $\Delta K_{\tau}$ under plane stress condition as shown in Figure 14c, in which the black-solidpoints represent the transition points. Note that the specimens in which transition was not observed in Figure 5 were plotted by $\Delta K_{\tau}$ of the following slip plane: $\Delta K_{\tau}$ of (111) and (111) planes for [110] $700^{\circ} \mathrm{C}$ specimen, and $\Delta K_{\tau}$ of (100) and (010) planes for [110]900 ${ }^{\circ} \mathrm{C}$ specimen because cubic slip was possibly activated at $900^{\circ} \mathrm{C}$ in this orientation specimen. Figure 15 suggests that stageII cracking occurs at low $\Delta K_{\tau}$ region because stage-II CPR is faster than stage-I CPR in this region, while stage-I cracking occurs at high $\Delta K_{\tau}$ region because stage-I CPR was faster than stage-II CPR in this region.

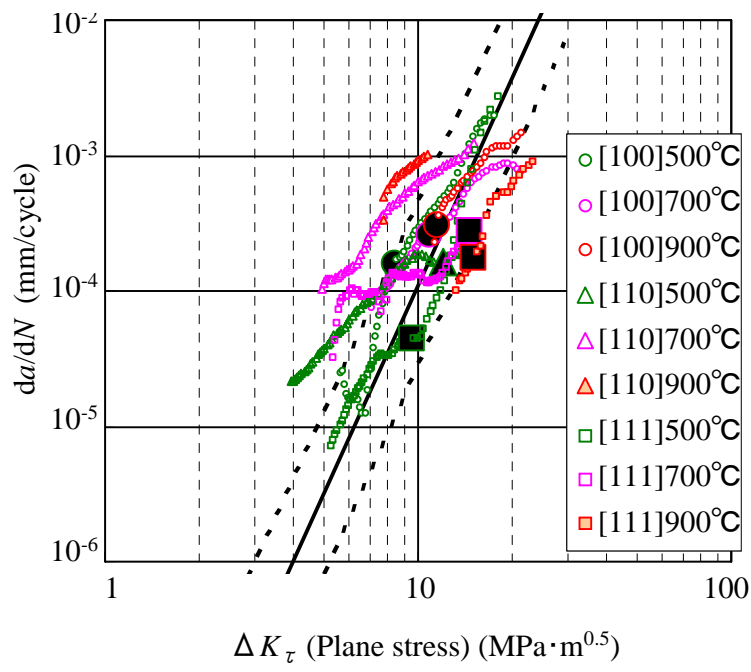

Figure 15 Stage-II crack propagation rates plotted against $\Delta K_{\tau}$ under plane stress condition.

\section{Conclusions}

Crack propagation tests were performed by using compact specimen made of single crystal superalloy CMSX-4. Three different orientation specimens were tested. The combinations of the loading direction and the machined notch direction are [010][100], [110][110] and [111][121]. Tests were performed under $10 \mathrm{~Hz}$ in air at room temperature, $500^{\circ} \mathrm{C}, 700^{\circ} \mathrm{C}$ and $900^{\circ} \mathrm{C}$ in each orientation specimen. The results were the following:

1. All specimens tested at room temperature showed stage-I fracture, while all specimens tested at elevated temperature showed stage-II fracture at the beginning of tests.

2. Mode I-III stress intensity factors of stage-I cracks were calculated by finite element analysis in which the experimentally obtained stage-I fracture surfaces were faithfully modeled three-dimensionally. Stage-I crack propagation rates were correlated in the range of a factor of 4 with resolved shear stress intensity factor on a slip plane parallel to the stage-I crack plane.

3. Stage-II crack propagation rates of all specimens were correlated in the range of a factor of 3 with energy release rate calculated using anisotropic elastic moduli. It was suggested that the difference of elastic moduli caused by the difference between specimen orientation and tested temperature influenced stage-II crack propagation rate.

4. At elevated temperature, stage-I fracture surfaces were sometimes observed near the specimen side faces. In some specimens, stage-I cracking nucleating near specimen side faces expanded to the interior with crack propagation. The transition from stage-II to stage-I cracking is related to resolved shear stress intensity factor range. The reason why stage-I cracking has occurred near specimen side faces is that the resolved shear stress intensity factor range under plane stress condition is higher than that under plane strain condition.

5. To evaluate the criterion of the cracking mode transition, stage-II crack propagation rates were plotted against resolved shear stress intensity factor range under plane stress condition. These stage-II data intersected with stage-I crack propagation rate data which were plotted against resolved shear stress intensity factor range. Crack propagation rate data when the transitions from stage-II to stage-I were observed at specimen side faces were located into the band of stage-I data, in spite of the fact that stage-II crack propagation rates differed from specimen orientations and tested temperatures.

\section{References}

1. H.L.Bernstein and J.M.Allen, "Analysis of cracked gas turbine blades”, Journal of Engineering for Gas Turbines and Power, Vol.114 (1992), pp.293-301.

2. D. M. Shah and D. N. Duhl, "The effect of orientation, temperature and gamma prime size on the yield strength of a single crystal nickel base superalloy”, Superalloy 1984, Edited by M. Gel1, et al, TMS-AlME, Warrandale, pp. 105

3. G. Bande and J. A. Nemes, "A new approach for single crystal materials analysis : Theory and application to initial yielding”, Journal of Engineering Materials and Technology Vol. 127(2005), pp. 119 
4. D. J. Duquette and M. Gell, "The effects of environment on the elevated temperature fatigue behavior of nickel-base superalloy single crystals”, Metallurgical transactions, Volume 3(1972), 1899-1905

5. G. R. Leverant and M. Gell, "The influence of temperature and cyclic frequency on the fatigue fracture of cube oriented nickel-base superalloy single crystals", Metallurgical and Materials Transactions A, Volume 6, Number 2, 367-371

6. D.W.Maclachlan and D.M.Konwles, "Fatigue behaviour and lifing of two single crystal superalloys", Fatigue \& Fracture of Engineering Materials \& Structures, Volume 24, Issue 8 (2001), pages 503-521

7. K. S. Chan, J. E. Hack and G. R. Leverant, "Fatigue crack propagation in Ni-base superalloy single crystals under multiaxial cyclic loads", Metallurgical Transactions A, Volume 17A(1986), 1739-1750

8. K. S. Chan, J. E. Hack and G. R. Leverant, "Fatigue crack growth in MAR-M200 single crystals", Metallurgical Transactions A, Volume 18A(1987), 581-591

9. K. S. Chan and G. R. Leverant, "Elevated-temperature fatigue crack growth behavior of MAR-M200 single crystals”, Metallurgical Transactions A, Volume 18A(1987), 593-602

10. A.Defresne and L.Remy, "Fatigue behaviour of CMSX 2 superalloy [001] single crystals at high temperature II: Fatigue crack growth”, Materials Science and Engineering A, Vol.129(1990), pp.55-64.

11. S.H.Ai, V.Lupinc and G.Onofrio, "Influence of precipitate morphology on high temperature fatigue crack growth of a single crystal nickel base superalloy"

12. B. A. Lerch and S. D. Antolovich, "Fatigue crack propagation behavior of a single crystal superalloy", Metallurgical Transactions A, Vol. 21, pp. 2169-2177(1990).

13. P. Shahinian, "Fatigue crack growth characteristics of hightemperature alloys”, Met. Technol. Vol. 5, no. 11, pp. 372380. Nov. 1978

14. M. B. Henderson and J. W. Martin, "The influence of crystal orientation on the high temperature fatigue crack growth of a Ni-based single crystal superalloy”, Acta mater. Volume 44, Number 1, pp. 111-126(1996)

15. V. Lupinc and G. Onofrio, "The effect of creep and oxidation on high-temperature fatigue crack propagation in $<001>$ loaded CMSX-2 superalloy single crystals", Materials Science and Engineering A, Vol. 202 pp. 76-83(1995).

16. P. A. S. Reed, X. D. Wu and I. Sinclair, "Fatigue crack path prediction in UDIMET 720 nickel-based alloy single crystals", Metallurgical and Materials Transactions A, Volume 31A(2000), 109-123

17. M.R.Joyce, X.Wu, P.A.S.Reed, "The effect of environment and orientation on fatigue crack growth behaviour of CMSX-4 nickel base single crystal at $650^{\circ} \mathrm{C}^{\prime}$, Materials Letters Vol.58 (2003), pp.99-103.

18. J.Telesman and L. J. Ghosn, "Fatigue crack growth behavior of PWA 1484 single crystal superalloy at elevated temperatures”, Journal of Engineering for Gas Turbines and Power, Volume 118(1996), 399-405

19. A. Sengupta, S.K.Putatunda, and M.Balogh, "Fatigue crack growth behavior of a new single crystal Nickel-based superalloy(CMSX-4) at $650^{\circ} \mathrm{C}$ ”, Journal of Material Engineering and Performance, Vol. 3 (1994), pp. 540-550.

20. B.F.Antolovich, A.Saxena, and S.D.Antolovich, "Fatigue crack propagation in single-crystal CMSX-2 at elevated temperature”, Journal of Materials Engineering and Performance, Vol.2 (4), pp489-496(1993).

21. L.Liu, N.S.Husseini, C.J.Torbet, W.-K.Lee, R.Clarke, J.W.Jones, T.M.Pollock, "In situ synchrotron X-ray imaging of high-cycle fatigue crack propagation in single-crystal nickel-base alloys”, Acta Materialia vol.59 (2011), pp.51035115.

22. M.Okazaki, M.Sakaguchi, and S.Yamanobe, "Fatigue crack propagation behavior significantly interacting with microstrucural units in thin wall Ni-base superalloy structures", $10^{\text {th }}$ International Gas Turbine Congress, IGTC11, Osaka, Japan, November.13-18, 2011.

23. H. Suzuki, S. Nishino and K. Matsuyama, "Fatigue crack growth behavior and fracture analysis in single crystal $\mathrm{Ni}$ base superalloy CMSX-4 at elevated temperature", Transactions of the Japan Society of Mechanical Engineers, Series A, Vol. 62(597), pp. 1146-1151, (1996).

24. Annual Book of ASTM Standards, E647, ASTM International.

25. D. Siebörgera, H. Knakeb and U. Glatzel, "Temperature dependence of the elastic moduli of the nickel-base superalloy CMSX-4 and its isolated phases", Materials Science and Engineering A, Vol. 298(2001), pp.26-33

26. K.S.Chan and T.A.Cruse, "Stress intensity factors for anisotropic compact-tension specimens with inclined cracks”, Engineering Fracture Mechanics, Vol.23, No.5, pp.863-874(1986).

27. H.Tada, P.C.Paris and G.R.Irwin, "The stress analysis of cracks handbook”, Del Research (1973).

28. MSC.Marc 2010. Online Manual, 2010, MSC software.

29. A.Hoenig, "Near-tip behavior of a crack in a plane anisotropic elastic body", Engineering Fracture Mechanics Vol.16, No.3, pp.393-403, 1982

30. Leslie Banks-Sills, Itai Hershkovitz, Paul A. Wawrzynek, Rami Eliasi, Anthony R. Ingraffea, "Methods for calculating stress intensity factors in anisotropic materials: Part I - $\mathrm{z}=0$ is a symmetric plane", Engineering Fracture Mechanics, Vol.72(2005), pp.2328-2358. 